\title{
Regional Cultural Identity and Visual Element Refinement --Taking Guangxi University Chongzuo Bridge mural design project as example

\author{
Xingguo $\mathrm{Xu}$
}

Guangxi Technological College of Machinery and Electricity, Nanning Guangxi, 530007, China

Keywords: Regional culture, Cultural identity, Cultural belt, Visual element, Refinement.

\begin{abstract}
This paper divides Guangxi regional culture into five regional cultural zones, studies the regional cultural characteristics of Guangxi, and expounds the three levels of regional cultural identity in Guangxi. Taking the design of "Chongzuoqiao Mural Painting Project of Guangxi University" as an example, the author designs and designs the visual elements with regional cultural characteristics and presents the cultural connotation of the times, and enhances the emotional experience of Guangxi regional culture core values and regional cultural identity.
\end{abstract}

\section{The concept of regional culture}

Regional culture refers to the unique region of the land of China has a long history, unique, inherited still play a role in the cultural tradition. Regional culture and nature, humanities, social environment are interrelated, is in the process of development continue to learn a variety of local ethnic style and cultural content to form a unique regional culture. Regional culture is based on the region, to the history of the main line to the scene as the carrier, to the reality of the appearance, is the social process to play a role in the human spirit of the general term. Reflecting the social outlook, national economic, political, religious beliefs and other cultural forms, but also contains the unique national religion, philosophy, customs, art and the entire value system of cultural origin. Therefore, in the course of the development of history by the combination of natural conditions and social conditions with the formation of the unique values of the nation's values, aesthetic concepts, customs.

\section{A Survey of Guangxi Regional Culture}

Guangxi Zhuang Autonomous Region referred to as "Gui", known as "Bangui" reputation, located in the southwest border of China, the Han population accounted for $62.8 \%$ of the total population, followed by Zhuang population accounted for 31.4\% of the total population, Ethnic groups living in ethnic minorities. The people of all ethnic groups have created a splendid national culture. Guangxi regional cultural characteristics embodied in the ancient Luo Yue culture, Zhuang Luo Yue ancestors mainly concentrated in the Guangxi Riverside River Basin and the southwest of Guizhou and the Red River Delta in Vietnam area, Luo Yue nationality because of its natural environment and the specific mode of production, to create A unique material culture and spiritual culture. Luo culture, including the rice culture, cotton culture, dragon boat culture, Huashan mural culture, shipping culture, pictorial square word, dragon mother culture, bronze culture, jade culture, smelting manufacturing culture, three circles view, sun culture, witch culture Worship culture and so on the Chinese civilization, Southeast Asian civilization and even the world civilization has a significant and far-reaching impact.

\section{Guangxi regional cultural identity}

Cultural identity refers to the individual's commitment to the culture and the inner commitment to maintain and innovate their own cultural attributes of the social psychological process. In general, ancestral identity, national identity, national identity and cultural identity is interdependent. 
With the development and utilization of regional cultural resources, the relevant disciplines theory and practice have been deepened and perfected and tend to be diversified. The author studies the regional cultural identity of Guangxi from the perspective of regional cultural characteristics of Guangxi, which is divided into three levels: natural element, human element and architectural element, and classifies each level. (Figure 1).

\section{Natural element level}

\section{Geography element}

Guangxi is located in southwest China, and Guangdong, Hunan, Guizhou, Yunnan, Hainan adjacent, is a subtropical monsoon climate area, perennial precipitation, Guangxi rivers, karst landform as a whole mountainous basin basin.

\section{Landscape element}

Guangxi karst landscape is widely distributed, the development of typical, strange scenery. Concentrated contiguous distribution in the southwest of Guangxi, northwest Guangxi, Guizhong, northeast of Guangxi. Towering peaks before and after the occlusion of layers of layers of the formation of several mountainous space effect, the mountain reflection in the river to form a spectacular mountain. Which Guilin landscape tourist area is a typical karst landform.

\section{Terraced fields element}

Longsheng terraced set of magnificent and beautiful in one, "the world's top of the terraced fields," the reputation of a layer from the foot of the mountain to the top of the mountain, layers of layers, the level of scattered. Its lines line of flowing water, its scale majestic spectacular.

Humanity element level

\section{Ethnic elements}

Guangxi is a multi-ethnic settlements, there are Han, Zhuang, Yao, Miao, Dong and other 12 ethnic groups. The culture between the various ethnic groups blend, creating the ancient bronze drums, Zhuang Jin, hydrangea and indigo national costumes and other national cultural products.

Guiliu dialect is a kind of southwest Mandarin, Guangxi is the most powerful Chinese dialect. Gui Liu Mandarin is divided into Jincheng River, Guilin, Liuzhou, then, and so on.

2.Zhuang brocade element

Zhuang Jin its main decorative elements for the grid geometric diamond-shaped, back, moire. Vivid patterns, structured, colorful, full of warm, cheerful national style, embodies the Zhuang people's pursuit of a better life and longing.

\section{Copper drum element}

Bronze drum shape like drums, drums for the key part of the decoration, the center is often accompanied by the sun pattern, the outside is decorated with halo, and drum edge close to the circle with a beautiful cast carving ornaments, the most is the frog, Knights, skirts, turtles, birds and so on. Reflecting the ancestors of the Zhuang people engaged in agricultural production activities in the worship of natural phenomena.

4.Stone carving element

Ningming Huashan rock painting is the representative of the Zuojiang rock paintings, is the Warring States period to the Eastern Han Dynasty Zhuang ancestors Luo Yue people's creation. 2016 was approved for inclusion in the World Heritage List. Guangxi cliff statues have boast feast stone statues, the largest number of Guilin statues, Li Huan statues, Zhang Xiaoxiang title praise, the early view of audio and video, Guan Xi sixteen like, Jingjiang Wangfu Qun Yin engraved like. Guilin, Guangxi, more than 2,000 pieces of stone, a wide variety of patterns, elegance of the people of stone inscription.

\section{Costume element}

Zhuang women make good cloth and Zhuang Jin, in the shoes, hats, chest pocket with colored silk embroidered on the pattern. Clothing made of green Dai Dai made of cloth, blue indigo is the most important color on the dress. With the self-woven cotton yarn woven out of the cloth, thick, solid, wear, and then dyed blue, black or brown.

6.Literary element 
Guangxi literature has Lingyi Ci and Lingxi five. Lin Gui Ci School is the most important part of the Ci Poetry in the late Qing Dynasty. Lin Gui Ci is headed by Wang Pengyun and Zhou Yi. Qing Dynasty Jiaqing Daoguang years Guangxi five "Tongcheng school" ancient writers collectively known as the Five Rendezvous.

\section{Opera element}

Guangxi opera has a classic handed down the Gui opera and Qi opera, homology of Cantonese opera and opera, from the soil opera, the bench to the drama, the priestly entertainment of the teacher drama, famous tea and color drama drama.

8.Folk-custom element

Guangxi folk custom in the production of the practice of the spring ravage plowing, worship Jingyang God, life customs have to respect the flower in order to fertility, the song and other spirits, worship custom worship, water worship, dragon worship, tree worship, flowers Worship, mine worship. Festivals have to do the Spring Festival dumplings cake, Dong year feast, Zhuang clan festival, Zhuang cattle soul section, Mao Nan family Halloween, Yao family Wang, Miao slope will be.

\section{Architectural element level}

\section{Traditional architecture}

Guangxi's national architecture do not have style, in the living customs with the ancient Baiyue national cultural factors. Among them, the Dong people superb skills, built a shelter wind and rain bridge and Fei Ge heavy eaves copper drum. Zhuang 's "dry - bar" architecture is an ancient Chinese architecture - an important form, and developed into one of the main forms of residence of the various ethnic groups in the South.

\section{Arcade}

Guangxi arcade around the main building is the former shop after the house, the next shop on the house. Generally used reinforced concrete structure, the column spacing is generally about 3 meters to 5 meters. Roof, balcony, stigma and other forms of different, with relief, Roman column, arched arched window decoration, the integration of Chinese traditional style and European classical architectural style.

3.Ancestral Hall

Guangxi ancestral hall has a bird's nest floor, honeycomb floor, Mo's Tusi office and so on.

4.Ancient city fortress

Ancient city of Guangxi fortress two thousand years ago in Guilin Xing'an Qincheng, is the reign of Emperor Qin Ling Huang camp site. 700 years ago, the Song Dynasty Jingjiang House, the existing engraved in the Guilin city parrot mountain south cliff on the "Jingjiang city map" is one of the earliest city map. (Figure 1) 


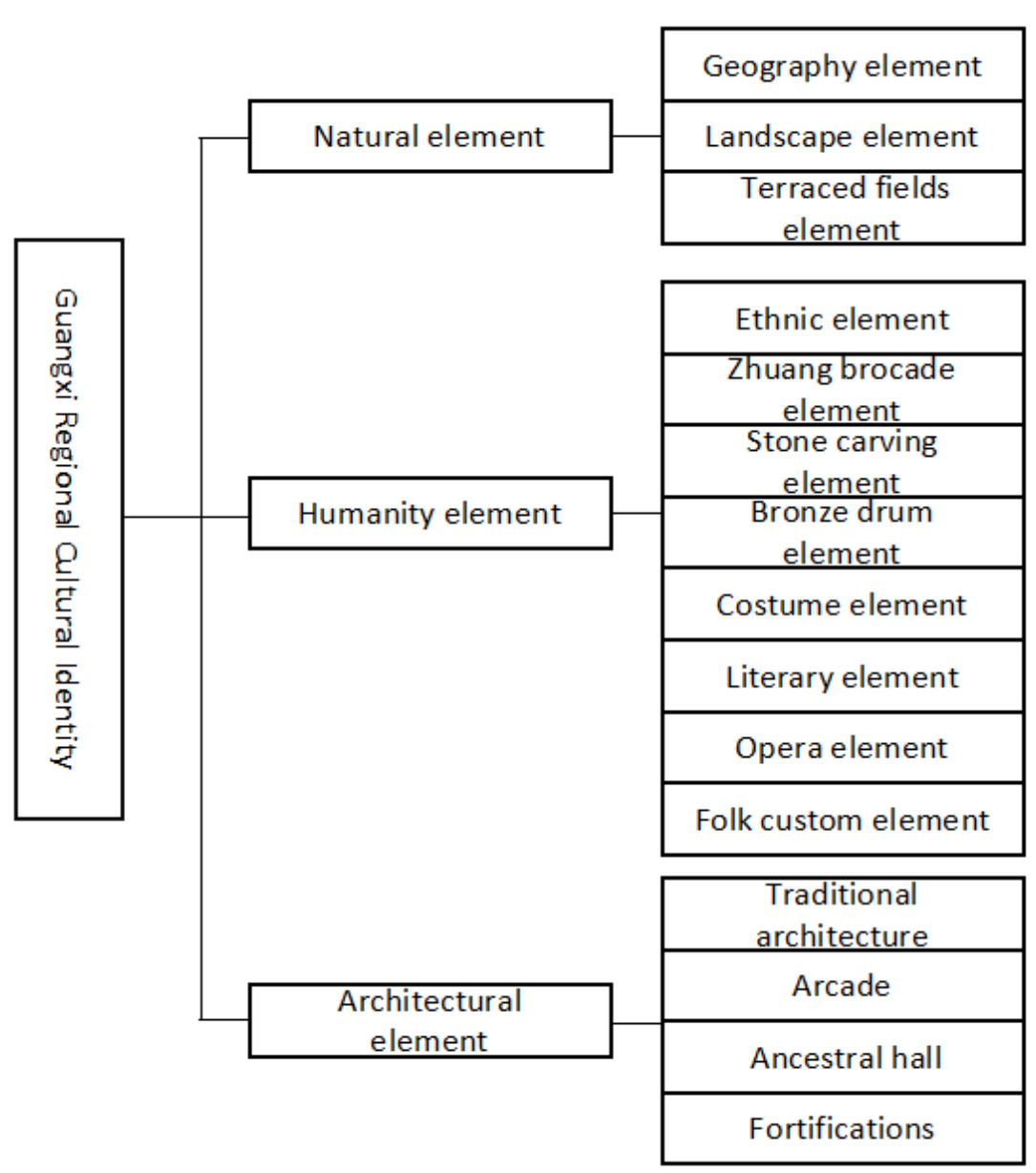

Fig. 1. structure chart of Guangxi regional culture identity

\section{Visual element refinement}

In the planning and design of the "Guangxi University Chongzuo Bridge murals" project at the beginning, around the unique geographical culture of Guangxi as a "visual element" for the positioning of research, digging Guangxi non-material cultural heritage, historical sites, national level to protect animals And other aspects of the subject matter, after repeated comparison, looking for regional cultural identity and differences in national culture, the Guangxi Ningming Huashan rock paintings, Guangxi Wuming March three song fair, Guangxi Beili bronze drum, Guangxi Chongzuo German days falls, Xiangyou Friendship and Guangxi Chongzuo white head monkey, located in Guangxi regional cultural image on behalf of elements.

\section{Visual element refinement}

\section{Grand and strapping Huashan rock painting}

Huashan rock murals are the cultural heritage of the ancestors of the Zhuang nationality, the World Heritage Convention in 2016 will be included in the Zuojiang Huashan rock paintings in the world of intangible cultural heritage list, become one of the important achievements of ancient Chinese civilization. Reflecting the ancient Guangxi ancestors rich and varied life scenes and the courage to fight the spirit. In the refinement of visual elements, the selection of the most tall and curious, body pliers of the body as a visual center, the design of the layout of the scene structured, dense and moderate, massive scenes reproduce solemn, cheerful ritual activities. (Figure 2) 


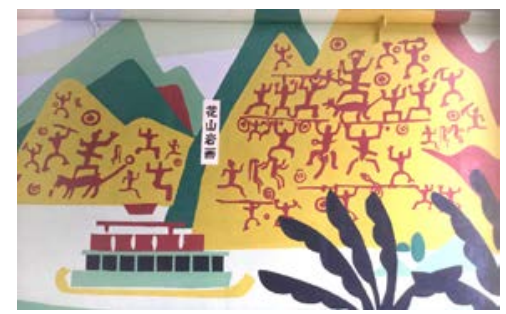

Fig. 2. Huashan rock painting scenery (part)

\section{Colorful Zhuang Town Song dyke}

The third day of March is the traditional festival of the Zhuang people in Guangxi, the Zhuang people called "Wo Po slope" or "Wo slope", intended to go to the PAC, the field to sing, so also known as "song fair" also known as to commemorate Liu Sanjie, So also called "song fairy". (Figure 3)

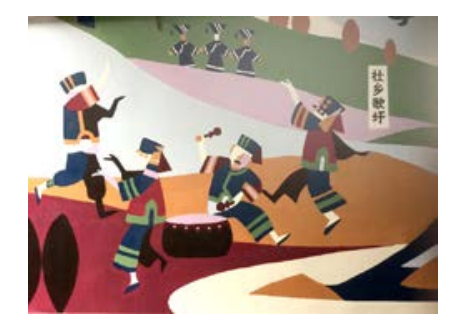

Fig. 3. Zhuang nation song dyke scenery (part)

3.Bronze drums decorated with magnificent

The bronze drum is the traditional instrument and power unit of Guangxi ethnic minorities. Bronze drums magnificent and full of national cultural characteristics, drums have the sun pattern, thieves, frogs, flying heron; body of the feathers dancing, dragon boat racing, drums sun pattern light and light body seamless, outside the sun Is a wide range of channels ranging from halo, narrow halo in the jagged pattern, circle pattern, dotted pattern and other patterns, wide halo decorated with rotating fly heron. Drums are also decorated with geometric pattern, arranged dragon boat racing realistic portrait, drums are decorated with feathers dance portrait. Drums are cast with four large frog statue, with horses, cattle, turtles, fish and other statues, full of life. Choose the sun pattern and bird shape as a visual element, like the ancient religious rituals in the sacrifice of the sun custom, the temple is located in the temple can view the sunrise, sunset mountains, the tree stood three sacrificial offerings and blood branches dedicated worship Corresponding to the ancient Zhuang people worship the sun connotation. (Figure 4)

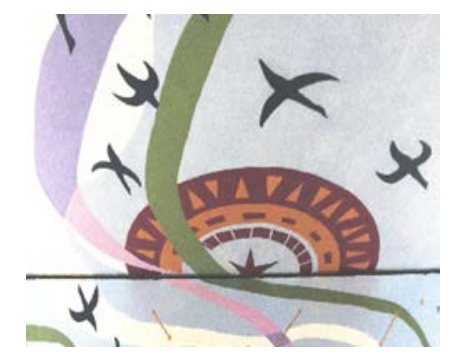

Fig.4. Bronze drum mural scenery(part)

4.Detian Waterfall of great momentum

De Tian Falls is located in Daxian County, Guangxi, China, for the national attractions. Is Asia's first, the world's fourth largest cross-border waterfalls, for China's national 4A-level tourist attractions. Waterfall magnificent, twists and turns, layers of falling, water potential agitation, heard a few miles. Waterfall when the river is anxious, when the time together, twists and turns in the towering ancient trees, more plants set off, birds low. River water suddenly meet the cliff, diarrhea and down, the rolling torrent, folded and complex poly. Tak Tin Falls magnificent magnificent, 
varied, clear water, never dry break. Choose the days of waterfall for the visual elements of Guangxi regional culture reflects the long history, never stop the spiritual connotation. (Figure 5)

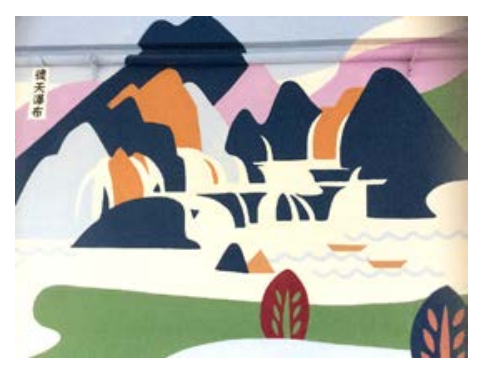

Fig. 5. Detian Waterfall mural scenery(part)

\section{Magnificent Youyi Guan}

Friendship began in the Han Dynasty, has 2000 years of history, is the only nine in China Guanzhong customs, known as "China South Gate," said. Guan Ming name "Friendship" for the Marshal Chen Yi personally written, the whole building is magnificent, is a major tourist attractions in Guangxi, the national key cultural relics protection unit list, is also the Guangxi Zhuang Autonomous Region patriotism education base. In the extraction of visual elements, the choice of friendship between the ancient city of the main fortress to reflect the Guangxi regional culture in the national security of the national integrity. (Figure 6)

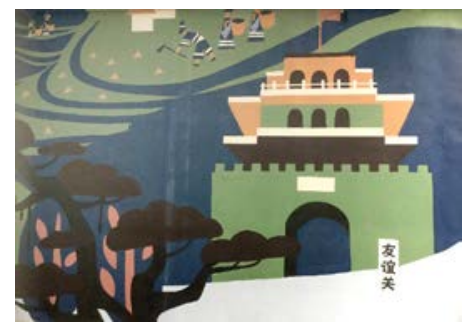

Fig. 6. Youyi Guan mural scenery (part)

6.Precious auspicious whiteheaded monkey

Whitehead monkeys distributed in Guangxi Chongzuo City and Ningming County, has been listed as the national level protection of wild animals and the "Convention on International Trade in Endangered Species of Wild Fauna and Flora". Choose the white-headed langur as a visual element, taking into account the lively and lovely nature of the white-headed langur and human nature is interlinked, while passing out the Guangxi regional culture of species living conditions, expressed the Guangxi people warm and friendly, The "good man" good meaning. The use of cartoon design techniques, showing the white-headed monkey naughty pro-pro, lively and lovely state. (Figure 7)

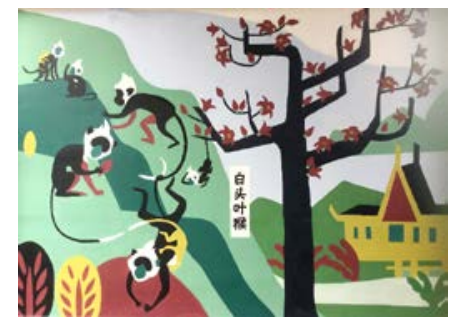

Fig.7. White-headed langur mural scenery(part)

\section{Visual element integration}

The visual elements extracted in the national culture are the identity of the local culture, with the visual and geographical characteristics of the visual performance. Guangxi University Chongzuo Bridge murals from the shape, color, style, content and other aspects of the Guangxi region has a landmark significance of the "visual symbols" that shape elements, the six groups of visual elements to interspersed and reorganized into the picture, Each group of visual elements next to the text description, will be representative of the Guangxi regional cultural elements can be presented in 
series. Which embodies the core values of Guangxi 's unique regional culture and the recognition of Guangxi' s regional culture. (Figure 8)

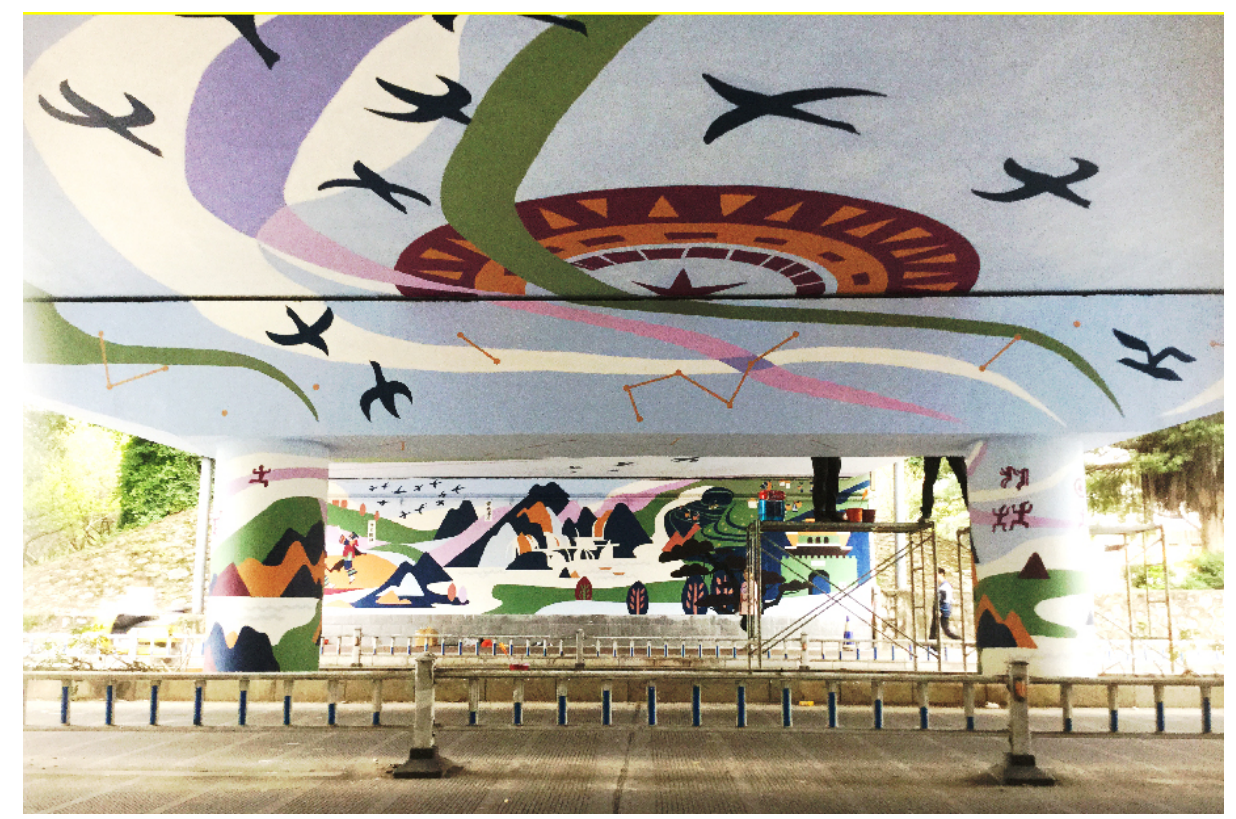

Fig. 8. Shuai Minfeng, Zhu Congcong, Ou Wensi, Liang Xiaocheng, Yuan Ye Guangxi University Chongzuo Bridge mural (Scenery)

\section{Conclusions}

In this paper, the "Guangxi University Chongzuo Bridge Mural Project" design, for example, through the division of Guangxi regional cultural belt, put forward three levels of research methods to explore the deep meaning of Guangxi regional culture, and thus the use of Guangxi regional culture visual elements, The project from the regional cultural identity to the visual elements of refining, integration, showing a clear regional cultural characteristics of Guangxi. This paper further analyzes the influence of the regional cultural phenomenon on the reconstruction of modern visual elements and discusses the artistic value and the change of the new elements of Guangxi 's characteristic regional culture from the theories of communication, advertising and semiotics.

\section{References}

[1] China 's regional culture editing committee. China 's regional culture Guangxi Vol. Beijing: Zhonghua Book Company, 2013.01.

[2] Sima Yunjie. Cultural sociology, Beijing: China Social Sciences Publishing House, 2001,8:195.

[3] Tang Zhengzhu. Give Full Play to the Cultural Advantages of Guangxi, Guangxi Daily, Mar. 29 2012.

[4] Wang Mengxiang. Memory of nation, Guangxi fine arts publishing house, 2009(8).

[5] Chen Hui: Folk Art Signs and Contemporary Advertising Design, Southeast University Press, Shanghai, 2009, Page 100. 